\title{
Genética de las adicciones
}

\author{
Ángela lbáñez Cuadrado \\ Hospital Universitario Ramón y Cajal. Universidad de Alcalá \\ Médico Adjunto de Psiquiatría. Unidad de Ludopatía. \\ Enviar correspondencia a: \\ Angela Ibáñez Cuadrado. Servicio de Psiquiatría. Hospital Universitario Ramón y Cajal. Crta. De Colmenar, km. 9,1. 28034 Madrid. \\ E-mail: aibanez.hrc@salud.madrid.org
}

\section{RESUMEN}

Las adicciones son trastornos psiquiátricos crónicos, que representan un serio problema de salud pública a nivel mundial. Estos trastornos tienen una elevada prevalencia y efectos negativos tanto individuales, como familiares y a nivel social, con un alto coste sanitario. Los estudios de epidemiología genética han puesto de manifiesto que las adicciones tienen una moderada a alta heredabilidad. Estas investigaciones también han evidenciado que los factores ambientales y genéticos contribuyen a las diferencias individuales en la vulnerabilidad a las adicciones. Por otra parte, los avances en la neurobiología de las adicciones junto con el desarrollo de nuevas tecnologías de genética molecular, han permitido la identificación de genes y vías implicados en el proceso de la adicción, dando lugar a la descripción de mecanismos moleculares comunes en las dependencias tanto a sustancias como conductuales. La identificación de las interacciones genes-ambiente es una cuestión crucial en la investigación futura. Otro objetivo prioritario de la investigación es la identificación de nuevas dianas terapéuticas para la prevención y el tratamiento.

Palabras clave: genética, vulnerabilidad, adicciones, trastornos adictivos, abuso de sustancias.

\section{ABSTRACT}

The addictions are common chronic psychiatric diseases which represent a serious worldwide public-health problem. They have a high prevalence and negative effects at individual, family and societal level, with a high sanitary cost. Epidemiological genetic research has revealed that addictions are moderately to highly heritable. Also the investigation has evidenced that environmental and genetic factors contribute to individual differences in vulnerability to addictions. Advances in the neurobiology of addiction joined to the development of new molecular genetic technologies, have led to the identification of a variety of underlying genes and pathways in addiction process, leading to the description of common molecular mechanisms in substance and behaviour dependencies. Identifying geneenvironment interactions is a crucial issue in future research. Other major goal in genetic research is the identification of new therapeutic targets for treatment and prevention.

Key words: genetics, vulnerability, addictions, addictive disorders, drug abuse.

\section{INTRODUCCIÓN}

$\mathbf{L}$ os revolucionarios avances en el campo de la genética humana han tenido importantes repercusiones en la teoría y en la práctica de la medicina en las últimas décadas. Buena prueba de ello es el anuncio en abril de 2003 de que el genoma humano estaba completo y de que el Proyecto Genoma Humano, iniciado en 1990 con una duración prevista de 15 años había finalizado dos años antes de lo estimado. De los 70.000 a 100.000 genes que se pensaba inicialmente que componían el genoma', en diez años se ha reducido la cifra a aproximadamente unos 25.000 genes ${ }^{2}$. Por otra parte, los grandes avances logrados para profundizar en el conocimiento de la variación genética humana fueron el acontecimiento científico del año 2007 según la revista Science ${ }^{3}$. Se espera que la influencia de la genética sea cada vez mayor en el futuro, no sólo para el diagnóstico y el conocimiento de la fisiopatología de las enfermedades, sino también para la prevención y el tratamiento de las mismas.

Esta "revolución" procedente de la genética ha ido impregnando todas las ramas de la medicina, y la psiquiatría no ha sido una excepción ${ }^{4}$. Las implicaciones en este campo se hacen más evidentes si se tiene en cuenta que del total de los genes que integran el genoma humano, cerca de la mitad se expresan exclusivamente en el cerebro ${ }^{5}$, lo que contribuye a explicar la enorme complejidad de este órgano y en 
consecuencia la de sus alteraciones, que constituirían la base de los trastornos mentales.

Entre los trastornos mentales, las adicciones ocupan sin lugar a dudas un lugar destacado, no sólo por la alta prevalencia que presentan en la población, sino por haberse convertido en uno de los más serios problemas de salud pública en el mundo. Según estudios de la Organización Mundial de la Salud (OMS), las tendencias actuales reflejan un aumento general del uso de drogas ilegales y de alcohol, así como un inquietante incremento del uso de drogas entre los sectores más jóvenes de la población. A pesar de estos datos, hasta épocas recientes las adicciones no se encontraban para algunos autores entre las prioridades de la investigación genética al considerar que en teoría eran trastornos en los que se podían aplicar medidas preventivas desde el punto de vista legal y que en última instancia dependían de una elección personal del individuo ${ }^{6}$. En la actualidad estamos asistiendo a un incremento en la investigación genética en las adicciones, en un intento de conocer mejor su fisiopatología y encontrar medidas terapéuticas más específicas y eficaces.

\section{LA COMPLEJIDAD GENÉTICA DE LAS ADICCIONES}

Las adicciones son enfermedades complejas desde el punto de vista fisiopatológico, derivado en gran parte de la complicada estructura y funcionamiento del órgano que les da origen, y que ha llevado a algunos autores a considerar el cerebro humano como "la máquina electroquímica más compleja del universo"7.

Las adicciones son también trastornos complejos desde el punto de vista genético, entendiendo como tales cualquier fenotipo que no exhibe un patrón de herencia mendeliana clásica atribuible a un único locus genético. Esta falta de relación entre genotipo y fenotipo puede deberse a que un mismo genotipo resulte en distintos fenotipos (por efectos ambientales, interacción con otros genes, etc.), o bien porque un mismo fenotipo pueda ser provocado por diferentes genotipos.

Uno de los factores que contribuyen a esta complejidad genética es el mecanismo desconocido de transmisión en las adicciones, una vez descartado el modelo "monogénico" que atribuye a un solo gen la causa de la enfermedad, pasando entonces al modelo "poligénico" que implicaría la acción de varios genes en la etiología; si este modelo fuera correcto, entonces los gemelos monocigóticos, que tienen un genoma idéntico al 100\%, deberían presentar una concordancia del $100 \%$ en cuanto al padecimiento de una determinada adicción, lo que no ha podido demostrarse en los estudios de epidemiología genética ${ }^{8}$. Como la acción de los genes no explica por sí misma la etiología de estos trastornos, se considera que existen otros factores de riesgo no genéticos (o ambientales) para el desarrollo de los mismos, surgiendo el modelo de herencia "multifactorial". Conviene precisar el concepto de "factores ambientales", ya que en este contexto son todos aquéllos que no son estrictamente heredables, incluyendo posibles factores biológicos prenatales o postnatales (infecciones, sufrimiento fetal, traumatismos, etc.), acontecimientos estocásticos en el DNA (como las mutaciones somáticas), así como todas las experiencias psicosociales desde las primeras etapas del desarrollo ${ }^{9}$. Se puede ir aún más lejos en la consideración del "ambiente", ya que para un determinado gen, la influencia de otros factores genéticos en su expresión y/o regulación se considera como un "factor ambiental". Por otro lado, cada vez son más las investigaciones que sugieren que los factores genéticos controlan en gran medida la influencia que los factores psicosociales tienen en cada individuo ${ }^{10}, 11,12,13$.

De esta manera, y en cuanto a su etiología, parece haber consenso entre los autores en considerar el modelo multifactorial como aquel que explica de forma más adecuada el desarrollo de las adicciones, de manera que es la interacción entre lo genético y lo ambiental lo que daría lugar al trastorno. Atendiendo al primer aspecto, se ha estimado que los factores genéticos contribuyen al $40-60 \%$ de la vulnerabilidad para el desarrollo de las adicciones, mientras que los factores ambientales explicarían el resto ${ }^{14}$. Ahora bien, dejando a un lado las estimaciones, y por la propia esencia de los trastornos adictivos que requieren el consumo de una sustancia por parte del individuo, no cabe duda de que los factores ambientales tienen una influencia decisiva en la etiología de las adicciones.

El modelo multifactorial surge precisamente de la observación de que la acción de los genes puede ser un elemento necesario pero no suficiente en el desarrollo de un determinado trastorno; es decir, que los genes no son la causa de la enfermedad sino que confieren una susceptibilidad para el desarrollo de la misma $^{15}$. Se han propuesto tres modelos para explicar la interacción entre genes y ambiente en la etiopatogenia de los trastornos mentales en general, también aplicable en las adicciones ${ }^{10}$ : a) El primer modelo, demasiado simplista, se basa en el efecto aditivo del componente genético y el ambiental, explicando la producción de la enfermedad mediante la simple contribución del efecto sumatorio de ambos componentes. b) El segundo modelo postula el control genético de la sensibilidad al ambiente, proponiendo que los genes controlarían el grado en el que un individuo es sensible a determinados aspectos del ambiente capaces de actuar como factores que aumentan o reducen el riesgo de desencadenar la enfermedad. c) El tercer modelo propone el control genético de la exposición al ambiente, es decir, que la influencia del genotipo en 
la susceptibilidad a desarrollar una enfermedad vendría dada por su capacidad para alterar la probabilidad de la exposición a circunstancias ambientales predisponentes. Probablemente una combinación de estos dos últimos modelos contribuiría a explicar mejor la interacción genes-ambiente en la etiología de las adicciones.

Otro aspecto a considerar y que contribuye a dotar de una mayor complejidad a los trastornos adictivos, deriva de la observación de que las drogas de abuso son sustancias que presentan una gran diversidad desde el punto de vista químico, y que ejercen su acción mediante su unión a distintas proteínas diana en el cerebro, provocando una diferente combinación de efectos fisiológicos y conductuales tras su consumo puntual. Ahora bien, a pesar de esta diferenciación en el mecanismo de acción, todas las drogas de abuso causan una serie de efectos comunes después de una exposición aguda y crónica a las mismas. Las sustancias adictivas provocan un refuerzo inmediato que favorece el consumo repetido y da lugar en individuos vulnerables al desarrollo de la adicción como trastorno. Evidencias procedentes de la investigación animal y más recientemente en humanos atribuyen el efecto reforzante de las drogas de abuso a su acción común sobre la vía dopaminérgica mesolímbica, de manera que cada droga, independientemente de su acción inicial, acaba provocando un incremento de la transmisión dopaminérgica a este nivel, ya sea directa o indirectamente. Por otra parte las drogas de abuso provocan síntomas emocionales negativos durante la abstinencia, con un periodo de sensibilización y un aprendizaje asociado a los estímulos ambientales relacionados con la droga. Todo ello se ha puesto en relación con su efecto sobre otras áreas cerebrales, como la amígdala, el hipocampo, el hipotálamo y algunas regiones del cortex frontal, algunas de ellas vinculadas a los circuitos involucrados en la memoria. Estos cambios adaptativos que se producen en el cerebro se relacionan con la aparición de "craving" y las recaídas a pesar de largos periodos de abstinencia, lo que contribuye a la cronicidad y refractariedad al tratamiento característicos de estos trastornos ${ }^{16}$. Por otra parte y en relación con lo anterior, algunos autores han sugerido que las diferencias individuales en la vulnerabilidad para las adicciones podría derivar en parte de diferencias individuales en los sistemas implicados en el proceso cerebral de la memoria, que tendrían a su vez un componente genético ${ }^{17}$.

Ahora bien, no son sólo las drogas de abuso las que son capaces de provocar los cambios en las mencionadas vías cerebrales dando lugar al desarrollo de una adicción con su característico cuadro clínico (deseo intenso de consumir, falta de control, abstinencia, tolerancia, abandono progresivo de otras fuentes de placer y persistencia en el consumo a pesar de consecuencias perjudiciales en todos los ámbitos) $)^{18}$, sino que también determinados comportamientos sin mediación de consumo de sustancias pueden dar lugar a efectos similares a este nivel. El prototipo de estas "adicciones sin sustancia", o conductas adictivas, es el juego patológico o ludopatía, cuyas similitudes con las adicciones químicas son en la actualidad ampliamente reconocidas ${ }^{19}$. Progresivamente se han ido sumando otras conductas que originan un cuadro clínico similar a pesar de la naturaleza diferente de la conducta, de forma análoga a lo que describíamos con las diferentes sustancias adictivas; entre dichos comportamientos se incluyen el comer compulsivo, las compras compulsivas y la adicción al sexo entre otras.

\section{EL COMPONENTE HEREDITARIO EN LAS ADIC- CIONES}

La investigación de la herencia de las adicciones se ha llevado a cabo a través de distintos estudios de epidemiología genética, que trata de estudiar la coincidencia en la presentación de los distintos trastornos en miembros de la misma familia (estudios familiares), con especial interés en los gemelos, así como en individuos adoptados en sus distintas modalidades, siendo los estudios en gemelos y adoptados los que permiten aclarar la contribución relativa de los factores ambientales y los genéticos.

En el caso de las adicciones los principales datos derivan de las diferencias de concordancia observada en gemelos monocigóticos en relación con los gemelos dicigóticos. La heredabilidad así obtenida (estimación del componente genético de susceptibilidad para el desarrollo de un trastorno, cuyo rango está entre 0 y 1), muestra valores variables según los distintos estudios. Así en alcoholismo los primeros estudios mostraban una concordancia en gemelos monicigotos del $30 \%$, sustancialmente menor que la observada en el trastorno bipolar y en la esquizofrenia, mientras que en los dicigotos era similar, alrededor del 16\%. También en esta patología son de obligada referencia los resultados del amplio estudio de adopción llevado a cabo por Cloninger et al., que permitieron a los autores delimitar dos tipos de alcoholismo: el tipo 1 en el que el componente hereditario sería mínimo, y el tipo 2 que estaría caracterizado por una alta heredabilidad, con transmisión de padre a hijo, inicio precoz y presencia frecuente de rasgos antisociales y conducta violenta ${ }^{20}$

Otra serie de estudios, comparando cohortes amplias de gemelos mono y dicigóticos, encuentran una heredabilidad para los trastornos adictivos de moderada a alta, oscilando entre 0.39 (para alucinógenos) y 0.72 (para cocaína) ${ }^{21}$.

También resultan de interés los estudios en gemelos que tratan de indagar sobre la heredabilidad en 
estadíos previos al desarrollo de la adicción. Así se ha mostrado que en las etapas iniciales de experimentación y primer contacto con sustancias el impacto de los factores genéticos es menor. También es escasa la influencia genética en la progresión del uso inicial al uso regular de la sustancia, si bien también resulta, como en el caso anterior, significativo ${ }^{22}$. Se ha observado alguna evidencia de heredabilidad en las diferencias individuales de respuesta a la administración aguda de una sustancia. Pero la mayor influencia genética en la vulnerabilidad para el desarrollo de las adicciones se encuentra en la transición del uso regular de una sustancia a la dependencia, con particular referencia a los últimos estadíos de la progresión en la adicción, que involucraría fenómenos relacionados con los procesos de la memoria ${ }^{17}$.

Los estudios en gemelos también han demostrado que parte de la vulnerabilidad genética para el desarrollo de las adicciones a sustancias ya sean legales o ilegales es compartida. Algunos autores sugieren que aunque parte de la predisposición genética puede ser específica para las distintas sustancias, parece tener mayor peso la heredabilidad de la susceptibilidad a las adicciones. De esta manera, las sustancias potencialmente más adictivas, como la cocaína y los opiáceos, se encuentran entre las que presentan una mayor heredabilidad, mientras que los alucinógenos, que tienen una menor capacidad adictiva, también muestran una heredabilidad menor. Así las variaciones genéticas que afecten funcionalmente a las bases neurobiológicas de la adicción, -como las vías del refuerzo, el control conductual, la compulsividad en la conducta, o la respuesta a la ansiedad y el estrés-, pueden mediar el desarrollo de estos trastornos ${ }^{17,21,23}$.

\section{ESTRATEGIAS DE IDENTIFICACIÓN DE GENES DE SUSCEPTIBILIDAD EN LAS ADICCIONES}

Una vez reconocido el papel que el componente genético tiene en la vulnerabilidad para el desarrollo de adicciones, los esfuerzos se centraron desde el inicio de la era de la genética molecular, en la búsqueda de las variantes genéticas que conferían dicha susceptibilidad. Con este objetivo se han utilizado distintas estrategias en las tres últimas décadas, entre las que podemos destacar por su valor histórico y/o rendimiento de los resultados obtenidos los estudios de ligamiento y asociación, la investigación en animales de experimentación, así como distintas modalidades de estudios genéticos funcionales.

\section{Estudios de ligamiento y de asociación}

Este tipo de estudios fueron los primeros en ponerse en marcha utilizando la tecnología de la genética molecular. En los estudios de asociación se compa- ran las frecuencias y distribuciones alélicas de marcadores genéticos polimórficos en dos poblaciones, una con un determinado trastorno y otra sin el mismo que se utiliza como control. Cuando la frecuencia de algún alelo marcador es significativamente mayor en la población de enfermos que en la de controles, el resultado es una "asociación positiva" y puede indicar entre otras interpretaciones una relación causal entre el alelo y el trastorno, o bien un efecto sobre la susceptibilidad para la enfermedad en estudio, aunque no sea la causa. Para una mayor rentabilidad de estos estudios se recomienda la utilización de poliformismos en "genes candidatos" (son aquellos que están potencialmente implicados en la etiología del trastorno que se pretende estudiar, por estar los productos de dichos genes -proteínas estructurales, enzimas, receptores, etc.- involucrados de alguna manera en su fisiopatología) ${ }^{24}$.

En los estudios de ligamiento se trata de identificar regiones cromosómicas que estén relacionadas con la etiopatogenia de un trastorno, mediante el uso de marcadores polimórficos de ADN cuya localización cromosómica está perfectamente establecida. Este tipo de estudios se basa en el postulado de Mendel que apunta la independencia de la segregación de los genes durante la meiosis, pero cuya excepción implica al material genético que esté situado en el mismo cromosoma cerca el uno del otro, que tendrán mayor probabilidad de segregar de forma conjunta en lugar de independiente, lo que se conoce como proceso de "ligamiento". Cuando el ligamiento resulta positivo se puede afirmar que dicho marcador y el gen de la enfermedad se localizan muy próximos en una región concreta del mismo cromosoma, y se pueden emplear diversas técnicas de genética molecular para estudiar la región e identificar el defecto genético causante del trastorno. Se pueden utilizar marcadores aislados, o bien un procedimiento denominado "positional cloning", en el que se utiliza de forma sistemática un mapa completo del genoma humano constituido por marcadores polimórficos claramente delimitados; de esta manera, cuando se detecta ligamiento en una determinada zona, se pueden identificar genes responsables de enfermedades según la posición que ocupan en el genoma, lo que permite estudiar enfermedades en ausencia de un conocimiento previo de su patogénesis ${ }^{25}$. Como muestra de este tipo de estudios podemos citar el estudio COGA (Collaborative Study on the Genetics of Alcoholism), una de las primeras iniciativas y ambicioso proyecto dirigido por el grupo de Reich para completar el análisis global del todo el genoma mediante la utilización de gran número de marcadores genéticos. Los resultados obtenidos mediante el análisis de 291 marcadores en 987 individuos de 105 familias, que fueron replicados posteriormente en una muestra ampliada de 1319 sujetos de 157 familias, permitieron localizar locus de susceptibilidad para alcoholismo en los cromosomas 1, 2 y 7; 
también encontraron en los casos más severos ligamiento con locus en los cromosomas 8 y 16, mientras que en el cromosoma 4 parecía existir un locus de protección contra el alcoholismo ${ }^{26}$. La disponibilidad de la base de datos de este estudio ha dado lugar a la publicación de más de 100 artículos en los últimos 10 años.

Otras iniciativas posteriores en el campo de las adicciones han utilizado mapas más completos del genoma humano, como las basadas en datos iniciales del Internacional HapMap Project. Ésta es una iniciativa que tiene como objetivo proporcionar un mapa del genoma humano conteniendo hasta 1 millón de SNPs (single nucleotide polymorphisms) (son un tipo de polimorfismo puntual caracterizado por el cambio en un único nucleótido y dan lugar a dos tipos de alelos) que puedan ser públicos y estar disponibles para la investigación genética. El organismo americano NIDA (National Institute on Drug Abuse) promueve estudios en adicciones utilizando marcadores que abarquen el genoma en su conjunto.

Algunas de las regiones que se han identificado como relacionadas con las adicciones utilizando este tipo de estrategias globales de búsqueda incluyen: El telómero del cromosoma 11p, donde se localiza entre otros el gen responsable de la síntesis del receptor D4 de dopamina (DRD4). En el cromosoma 4q la región que contiene el gen responsable de la síntesis de la enzima alcohol deshidrogenasa, así como otra región más cercana al centrómero que contiene el gen del receptor GABA-A ${ }^{21}$. Entre los genes candidatos que se han visto involucrados en las adicciones por la convergencia de resultados positivos en diversos estudios, se encuentran el gen del receptor D2 de dopamina (DRD2) localizado en el cromosoma 11, y el gen de la enzima catecol-O-metiltransferasa (COMT) implicada en el metabolismo de la dopamina y que se localiza en el cromosoma $22^{27}$.

\section{Investigación en animales de experimentación}

Este tipo de estudios se puede contemplar desde dos perspectivas complementarias. Por un lado se han desarrollado modelos animales de adicción que han resultado razonablemente satisfactorios para el estudio de esta patología, mediante el estudio por ejemplo de la actividad motora del animal en respuesta a la administración de una droga (la mayoría de las sustancias de abuso incrementan la actividad motora tras el consumo agudo de las mismas), o bien el progresivo incremento en la actividad locomotora (sensibilización) que ocurre con la exposición repetida a la droga. En ambos casos se basa a nivel teórico en que la respuesta motora está mediada por el sistema dopaminérgico mesolímbico, implicado a su vez en el refuerzo y la adicción. Otros modelos animales se basan en la localización preferente condicio- nada, donde el animal aprende a preferir el ambiente asociado a la exposición a la droga, así como en tests conductuales que incluyen la autoadministración oral, intravenosa o intracraneal de la sustancia en estudio y en los paradigmas de refuerzo condicionado ${ }^{10}$.

Otra vía de investigación con animales en las adicciones tienen el objetivo de estudiar la expresión génica, debido al alto nivel de similitud a nivel génico y cromosómico entre los humanos y otros animales. Así, alrededor del 85\% de los genes encontrados en el ratón, se hallan también en humanos. Los modelos animales más extensamente utilizados incluyen dos tipos de ratones: el ratón transgénico y el ratón "knockout". En el genoma de los primeros se ha insertado un gen alterado (por ejemplo un oncogen) o un gen de otra especie, de tal forma que se pueda analizar el efecto del mismo sobre el funcionamiento celular y la fisiología del animal, así como la respuesta a diferentes drogas de abuso. En el segundo caso, se han eliminado las dos copias de uno de los genes del genoma del animal que se considera como gen candidato en adicciones, es decir, son animales que carecen de un gen específico y, por lo tanto, no pueden sintetizar una proteína específica. De esta manera este tipo de ratones permiten investigar los efectos de mutaciones que afectan al funcionamiento normal de un gen ${ }^{28}$. La utilización de ratones "knockout" en el campo de las adicciones ha permitido por ejemplo la identificación del receptor opioide $\mu$, el transportador de dopamina, el receptor cannabinoide CB1 y el receptor nicotínico de acetilcolina $\beta 2$ como dianas mediadoras del refuerzo y otros efectos de los opiáceos, estimulantes, cannabinoides y nicotina respectivamente ${ }^{14}$.

\section{Estudios genéticos funcionales y otras tecno- logías}

Incluyen técnicas dirigidas al estudio de la expresión génica, técnicas de microarray y proteómica, con el objetivo de identificar genes candidatos y proteínas cuyos niveles de expresión cambien de modo significativo entre los diferentes estados de la adicción. Las técnicas de microarray permiten el estudio de un gran número de polimorfismos a la vez, lo que proporciona una valiosa información que no siempre es fácil de interpretar.

El efecto de una droga sobre la expresión génica puede proporcionar también claves en el estudio de la fisiopatología y la genética de las adicciones. A modo de ejemplo y siguiendo esta línea de investigación se han identificado en humanos vulnerables a sustancias determinados haplotipos (combinación de alelos de diferentes locus dentro del mismo cromosoma) específicos en el cromosoma 7 del gen que sintetiza el receptor NrCAM (nerve cell surface adhesión molecule/receptor); dicho gen se había relacionado pre- 
viamente con una expresión diferenciada en ratones tratados con morfina ${ }^{29}$.

\section{OTROS GENES IMPLICADOS EN LAS ADICCIONES}

En la literatura científica hay recogidos datos sobre la implicación de un gran número de polimorfismos en las adicciones, en particular desde que se aplican técnicas de microarray en estas investigaciones, lo que ha dado lugar a la identificación de nuevos genes candidatos. En un artículo reciente, los autores revisan los datos disponibles, identificando hasta 1500 genes relacionados con las adicciones en humanos; tras la realización de un metaanálisis encontraron 396 genes en los que había evidencia por parte de dos o más fuentes independientes, a través de los cuales identificaron 18 vías potencialmente implicadas en los mecanismos cerebrales de la adicción. De ellas, cinco vías resultaron ser comunes en distintas adicciones (cocaína, alcohol, opiáceos, nicotina) ${ }^{29}$.

Además de los genes mencionados anteriormente como potencialmente implicados en la susceptibilidad genética a las adicciones (como el DRD2, DRD4, y COMT), también se han identificado otros genes que podrían estar relacionados con el desarrollo de las mismas. Uno de ellos se encuentra en relación con el GABA, principal neurotransmisor inhibidor en el cerebro. El alcohol y las benzodiacepinas son capaces de actuar sobre el receptor GABA-A facilitando su efecto inhibidor sobre las neuronas, mostrando ambas sustancias tolerancia cruzada. Se ha descrito que las variaciones en la respuesta a alcohol en humanos puede tener un componente genético y estar mediadas por diferencias genéticas en dicho receptor. La región $\alpha 2$ del mismo se ha localizado en el cromosoma 4 , mientras que la $\alpha 6$ se ha situado en el cromosoma $5^{21}$

Los genes de la enzima alcohol deshidrogenasa (ADH1B) y aldehido deshidrogenasa (ALDH2) son dos genes de gran interés para las adicciones ya que son responsables de la síntesis de enzimas implicadas consecutivamente en el metabolismo del alcohol. La ADH metaboliza etanol a acetaldehído, un producto tóxico intermedio que se convierte a acetato por la acción de la ALDH. Su interés procede de las variaciones genéticas descritas en humanos que confieren un efecto de protección contra el desarrollo de alcoholismo, ya que tanto una alta actividad de ADH1B como una baja actividad de ALDH2, mediadas ambas por polimorfismos funcionales en dichos genes, dan lugar a la acumulación de acetaldehído, producto que en presencia de alcohol provoca una reacción similar al efecto del disulfiram. En países del este asiático como Japón, ambos polimorfismos son abundantes en la población, lo que confiere un efecto protector contra el alcoholismo ${ }^{21}$.

Otros genes de los que hay datos apuntando a su posible papel en la génesis de las adicciones son los ligados a factores neurotróficos como el BDNF y el GDNF: Los ratones "knockout" de BDNF muestran una respuesta reducida a opiáceos y cocaína, mientras que los "knockout" de GDNF muestran mayor respuesta. Variaciones genéticas en receptores serotonérgicos como el receptor de serotonina $1 \mathrm{~B}$ y el transportador de serotonina, también han sido relacionados en algunos estudios con las adicciones, así como el neuropéttido Y (NPY), el trasportador prolinacisteína, y factores de transcripción como el $\Delta$ FosB y el CREB $^{14,29}$

\section{CONCLUSIONES}

Aunque se han producido importantes avances en la investigación genética en las adicciones y el componente hereditario es ampliamente reconocido, la complejidad de estas patologías puede ser en parte responsable de que los resultados no hayan sido proporcionales al esfuerzo realizado. Los resultados contradictorios de los estudios de ligamiento y asociación con marcadores genéticos polimórficos, algunos mostrando hallazgos positivos de dudosa relevancia (por ejemplo con polimorfismos que carecen de traducción funcional) y otros incapaces de replicar los descubrimientos previos, han puesto en evidencia la complejidad de la genética de estos trastornos ya que son muchos los genes que pueden estar implicados interactuando con factores ambientales de una manera difícil de esclarecer con las técnicas actuales.

La investigación genética en el futuro podrá revelar claves que permitan integrar los hallazgos sobre variaciones genéticas identificadas en las adicciones en relación con los procesos neurobiológicos del refuerzo, el control conductual y la respuesta a la ansiedad y al estrés, mecanismos todos ellos implicados en la vulnerabilidad para las adicciones y el proceso de recuperación.

Por otra parte, la mayor sofisticación de las técnicas genéticas y del valor predictivo de los modelos animales en adicciones, contribuirá sin duda a identificar factores genéticos de susceptibilidad que ayudarán a esclarecer la fisiopatología de las mismas, dando lugar a la identificación de nuevas dianas terapéuticas para la prevención, y el tratamiento más específico tanto a corto como a largo plazo de estas patologías. 


\section{REFERENCIAS}

1. Rowen L, Mahairas G, Hood L. Sequencing the Human Genome. Science 1997; 278: 605-607.

2. Lupski JR. Structural Variation in the Human Genome. The New England Journal of Medicine 2007; 356: 1169.

3. Pennisi E. Breakthrough of the year. Human genetic variation. Science 2007; 318: 1842-3.

4. Payne CS, Roses AD. The Molecular Genetic Revolution. Its Impact on Clinical Neurology. Arch Neurol 1988; 45: 1366-1376.

5. Adams MD, Dubnick M, Kerlavage AR, Moreno R, Kelley JM, Utterback TR, et al. Sequence identification of 2.375 human brain genes. Nature 1992; 355: 632-634.

6. Merikangas KR \& Risch N. Genomic priorities and public health. Science 2003; 302: 599-601.

7. Strumwasser $F$. The relations between neuroscience and human behavioral science. J Exp Anal Behav 1994; 61 (2): 307-317.

8. Plomin R, Owen MJ, McGuffin P. The genetic basis of complex human behaviors. Science 1994; 264: 1733-1739.

9. Plomin R. Beyond nature versus nurture. En: Hall LL, Ed. Genetics and Mental Illness. Evolving Issues for Research and Society. New York: Plenum Press, 1996; 29-50.

10. Kendler KS, Eaves LJ. Models for the joint effect of genotype and environment on liability to psychiatric illness. Am J Psychiatry 1986; 143: 279-289.

11. Bergeman CS, Plomin R, Pedersen NL, McClearn GE, Nesselroade JR. Genetic and environmental influences on social support: The Swedish Adoption Twin Study of Aging (SATSA). J Gerontol 1990; 45: 101-106.

12. Kessler RC, Kendler KS, Heat AC, Neale MC, Eaves LJ. Social support, depressed mood, and adjustment to stress: A genetic epidemiologic investigation. J Pers Soc Psychol 1992; 62: 257-272.

13. Kendler KS. Social Support: A Genetic-Epidemiologic Analysis. Am J Psychiatry 1997; 154/10: 1398-1404.

14. Nestler EJ. Genes and adicction. Nature Genetics 2000; 26: 277-281.

15. Kaufmann CA, Johnson JE, Pardes H. Evolution and revolution in Psychiatric Genetics. En: Hall LL, Ed. Genetics and Mental IIIness. Evolving Issues for Research and Society. New York: Plenum Press, 1996; 5-28.

16. Nestler EJ. Is there a common molecular pathway for addiction? Nature Neuroscience 2005; 8: 1445-9
17. Uhl GR. Molecular genetic underpinnings of human substance abuse vulnerability: likely contributions to understanding addiction as a mnemonic process. Neuropharmacology 2004; 47: 140-7.

18. Organización Mundial de la Salud. Décima Revisión de la Clasificación Internacional de las Enfermedades. Trastornos mentales del comportamiento y desarrollo. Descripciones clínicas y pautas para el diagnóstico. Madrid: Meditor, 1992.

19. Blanco C, Moreyra P, Nunes EV, Saiz-Ruiz J, Ibanez A."Pathological gambling: addiction or compulsion?" Semin Clin Neuropsychiatry. 2001; 6(3): 167-176.

20. Cloninger CR, Bohman M, Sigvardsson S. Inheritance of alcohol abuse: Crossfostering analysis of alcoholic men. Arch Gen Psychiatry 1981; 38: 861.

21. Goldman D, Oroszi G, Ducci F. The Genetics of Addictions: Uncovering the genes. Nature Reviews 2005; 6: 521-32.

22. Kendler KS, Karkowski LM, Neale MC, Prescott CA. Illicit psychoactive substance use, heavy use, abuse, and dependence in a US population-based sample of male twins. Arch Gen Psychiatry 2000; 57: 261-9.

23. Goldman D, Bergen A. General and specific inheritance of substance abuse and alcoholism. Arch Gen Psychiatry 1998; 55: 964-5.

24. Saiz Ruiz J., Ibáñez Cuadrado A. "Genética molecular y Psiquiatría". Serie Nuevas fronteras en Psiquiatría. Barcelona: Ediciones Doyma, S.A., 1997.

25. Collins FS. Positional cloning: Let's not call it reverse any more. Nature Genetics 1992; 1: 3-6.

26. Reich T. A genomic survey of alcohol dependence and related phenotypes: results from the Collaborative Study on the Genetics of Alcoholism (COGA). Alcohol Clin Exp Res 1996; 20 (8 Suppl):133A-137A.

27. Uhl GR, Ping Liu QR, Naiman D. Substance abuse vulnerability loci: converging genome scanning data. Trends in Genetics 2002; 18: 420-5.

28. Pérez de Castro I, Ibáñez A. Bases biológicas de la herencia y herramientas genético-moleculares para el estudio de las bases genéticas de las enfermedades psiquiátricas. En: Fañanás L, Saiz J, Eds. Manual de Introducción a la Genética en Psiquiatría. Barcelona: Masson, S.A., 2000. Págs.: 1-36

29. Li CY, Mao X, Wei L. Genes and (Common) Pathways Underlyng Drug Addiction. PLoS Comput Biol 2008; 4(1): e2. doi:10.1371/journal.pcbi.0040002 
